\title{
Inhibition of surface bound carbonate stabilization of tetragonal zirconia
}

\author{
Nielsen, Mette Skovgaard; Almdal, Kristoffer; Lelieveld, A. van
}

Published in:

Journal of Materials Science

Link to article, DOI:

10.1007/s10853-011-5488-6

Publication date:

2011

Document Version

Early version, also known as pre-print

Link back to DTU Orbit

Citation (APA):

Nielsen, M. S., Almdal, K., \& Lelieveld, A. V. (2011). Inhibition of surface bound carbonate stabilization of tetragonal zirconia. Journal of Materials Science, 46(16), 5460-5465. https://doi.org/10.1007/s10853-011-5488-6

\section{General rights}

Copyright and moral rights for the publications made accessible in the public portal are retained by the authors and/or other copyright owners and it is a condition of accessing publications that users recognise and abide by the legal requirements associated with these rights.

- Users may download and print one copy of any publication from the public portal for the purpose of private study or research.

- You may not further distribute the material or use it for any profit-making activity or commercial gain

- You may freely distribute the URL identifying the publication in the public portal

If you believe that this document breaches copyright please contact us providing details, and we will remove access to the work immediately and investigate your claim. 


\title{
Inhibition of surface bound carbonate stabilization of tetragonal zirconia
}

\author{
M. Skovgaard \\ DentoFit A/S, Frederiksborgvej 399, 4000 Roskilde, Denmark \\ $\&$ \\ Department of Micro- and Nanotechnology, Technical University of Denmark, \\ Frederiksborgvej 399, 4000 Roskilde, Denmark \\ ms@dentofit.com, direct: +45 467742 84, fax: +45 46774791
}

\section{K. Almdal}

Department of Micro- and Nanotechnology, Technical University of Denmark, Frederiksborgvej 399, 4000 Roskilde, Denmark

kral@nanotech.dtu.dk

\author{
A. van Lelieveld \\ DentoFit A/S, Frederiksborgvej 399, 4000 Roskilde, Denmark \\ avl@aneedle.net
}

\begin{abstract}
Water is known to initiate a tetragonal to monoclinic phase transformation in zirconia particles.

Carbonates on the zirconia surface react with water molecules and hence reduces the transformation rate. This study investigates the possibility of inhibition of the reaction between surface carbonates and water in order to increase the transformation rate in the zirconia crystals. It was found possible to limit the reaction by reacting the surface carbonates with alcohols, a thiol and a primary amide prior to reaction with water. It was also concluded that di- and trialcohols are able to stabilize the tetragonal phase, probably as a results of induced lattice strain.
\end{abstract}

Keywords: zirconia, surface carbonates, phase transformation

\section{Introduction}

A problem with dental resin composites is the polymerization shrinkage, which results in loosening of the filling from the tooth or induced crack formation. The formation of a crack can give raise to discoloration due to colorants from e.g. coffee and red wine entering the crack or - worse - to secondary caries and infections of the dental pulp due to bacteria [1]. 
We have developed an expandable metastable tetragonal zirconia filler, which transforms into the lower density monoclinic phase upon reaction with water or $\mathrm{HCl}$, and thereby, seen for the composite as a whole, is able to counteract the polymerization shrinkage of the monomer matrix. The tetragonal to monoclinic $(\mathrm{t} \rightarrow \mathrm{m})$ phase transformation is accompanied by a $4 \%$ decrease in density. This expansion is for instance used in transformation toughening of ceramic materials [2].

In previous work we have tested the potential of the filler to counteract the polymerization shrinkage by initiating the phase transformation by water diffusing into the polymer matrix [3] and found that the overall shrinkage of a composite containing $42 \mathrm{wt}-\%$ zirconia stored in water at $40^{\circ} \mathrm{C}$ was reduced with $44 \%$ within the first 7 days comparing with an equivalent sample stored in air. However, the most desirable scenario is to initiate phase transformation of the tetragonal zirconia filler during polymerization of the organic matrix. We envisage that simultaneous phase transformation initiation and curing can be achieved by adding a photoacid generator, which releases $\mathrm{HCl}$ or water upon illumination [4].

Water is known for the ability to induce phase transformation of tetragonal zirconia [5]. High sensitivity of the zirconia filler towards water is however important as the activity of water in the composite is low due to the hydrophobicity of the resin. It is known from literature that carbonates on the zirconia surface react with water molecules [6]. This limits the water availability for phase transformation initiation. In this study we investigate how this undesirable side reaction can be inhibited in order to increase the sensitivity of the metastable tetragonal zirconia filler towards water and $\mathrm{HCl}$ and hence increase the phase transformation rate.

\section{Experimental}

All chemicals were supplied by Sigma-Aldrich (St. Louis, MO, USA) and used as received. Highly porous (specific surface area of $\sim 150 \mathrm{~m}^{2} / \mathrm{g}$ ) nanocrystalline tetragonal zirconia powders were synthesized as previously described $[7,8]$ by controlled hydrolysis of $\mathrm{ZrOCl}_{2}$ followed by careful calcination. The synthesized $\mathrm{t}-\mathrm{ZrO}_{2}$ powders were kept in water-free environment for further treatment to prevent the $\mathrm{t} \rightarrow \mathrm{m}$ phase transformation which is induced by exposure to water vapor $[9,10]$.

\section{Test of different activators}

$1 \mathrm{mmol}$ of the potential activators (as described in Tab. 1) was mixed with $500 \mathrm{mg}$ of a dimethacrylate monomer mixture (bisphenol-A diglycidyl ether dimethacrylate, urethane dimethacrylate, and triethylene glycol dimethacrylate Bis-GMA/UDMA/TEGDMA, 36/44/20 wt \%) and a photo polymerization system (camphorquinone and ethyl 4-dimethylamino benzoate - CQ/DABE both 0.5 $\mathrm{wt} \%$ ). In a glove box $200 \mathrm{mg}$ of the metastable tetragonal zirconia powder and $100 \mathrm{mg}$ of 2-(4-methoxystyryl)-4,6-bis(trichloromethyl)-1,3,5-triazine were added. Tested solid activators were dissolved in the dimethacrylate matrix prior to mixing with the zirconia powder. 
A sample of this mixture was placed between two glass plates and cured for 30 min using blue light $\left(1,100 \mathrm{~mW}\right.$ ) from a Bluephase ${ }^{\circledR}$ light probe (Ivoclar Vivadent, Liechtenstein). The phase transformation is initiated during curing. The cured samples were then subjected directly to the X-ray diffraction (XRD) measurement for phase analysis. The polymer matrix prevents the tetragonal crystals from undergoing phase transformation initiated by humidity.

Also a reference sample without addition of any potential activator were prepared

\section{Samples for water aging}

In inert atmosphere a sample of $1 \mathrm{~g}$ tetragonal zirconia was suspended in anhydrous methanol. The suspension was filtered and left to dry in the filter overnight in inert atmosphere. $200 \mathrm{mg}$ of this methanol treated zirconia were matrix dispersed (as described above) and cured. Furthermore, equivalent samples were prepared containing $200 \mathrm{mg}$ unmodified zirconia and $500 \mathrm{mg}$ dimethacrylate mixture. Such samples are termed matrix dispersed zirconia. The matrix dispersed samples were stored in water at $40{ }^{\circ} \mathrm{C}$ and following subjected directly to the $\mathrm{X}$ ray diffraction (XRD) measurement for phase analysis.

\section{Characterization}

\section{X-Ray Diffraction (XRD) evaluation}

XRD patterns were scanned in 0.05 steps $(2 \theta)$, in the $2 \theta$ range from $27^{\circ}$ to $33^{\circ}$. The XRD patterns were analyzed using $\mathrm{WinX}^{\mathrm{POW}}$ software. The monoclinic volume fraction $\left(\mathrm{v}_{\mathrm{m}}\right)$ were calculated from the integral intensities of the monoclinic diffraction lines $\left(\begin{array}{lll}-1 & 1 & 1\end{array}\right)$ and $\left(\begin{array}{lll}1 & 1 & 1\end{array}\right)$ and the tetragonal diffraction line (1 0 1), following the procedure proposed by Toraya et al [11].

\section{Fourier transform infrared spectroscopy}

Fourier transform infrared spectrometry (FTIR) was performed using a PerkinElmer Spectrum one FTIR spectrometer. The samples for analysis were prepared by pressing a pellet with a diameter of $1 \mathrm{~cm}$ of $30 \mathrm{mg}$ zirconia and placing it between two $\mathrm{CaF}_{2}$ windows in an airtight holder. All handling was done in a glove box ( $<10 \mathrm{ppm}$ water). Spectra were collected within the range from 900 to $4000 \mathrm{~cm}^{-1}$ with averaging over 32 scans.

\section{Autosorbtion: determination of water adsorption}

The amount of water adsorbed on the zirconia surface at a given partial pressure can be determined using a Quantachrome XT autosorb analyzer, (Quantachrome Instruments, Florida, US). A sample of the zirconia powder is kept at $0^{\circ} \mathrm{C}$ (ice bath) during the experiment. In order to avoid premature phase transformation it is necessary to use a seal that only opens in the autosorbtion machine. This way the sample can be kept under an inert atmosphere or vacuum until measurement starts and again after the sample is removed from the machine. The zirconia sample is evacuated to the relative pressure, $\mathrm{P}=0.01 \times \mathrm{P} 0$; where $\mathrm{P} 0$ is the ambient pressure. The sample is then titrated with water in gaseous form by the procedure of finding a relative pressure and then noting the amount of water necessary to get 
this pressure. At a given end-point (a given p/p0) the sample was re-evacuated and taken to a glove box. The zirconia was matrix dispersed as described above and subjected directly to the XRD measurement for phase analysis.

\section{Results}

\section{Triazine tests}

The effect of addition of different potential activators on light initiated phase transformation is listed in Tab. 1. It is observed that besides from some of the alcohols and octane thiol only acetamide is able to activate the zirconia. Out of the tested activators 1,5-pentanediol results in the highest monoclinic volume fraction in the samples. For the reference sample without any activator added, very little phase transformation was detected even after $2 \mathrm{~h}$ of light exposure.

\section{Effect of activators}

The XRD patterns of the water stored matrix dispersed zirconia are illustrated in Fig. 1. The methanol treated zirconia has a $v_{m}=0.67$ after water storage for 2 days and already after $8 \mathrm{~h}$ the sample has a $v_{m}=0.57$. The untreated samples, however, need more than 21 days to reach $v_{m}=0.47$. From Fig. 1 it is observed that the reference sample only contains traces of the monoclinic phase prior to water storage and the tetragonal 101 reflection of zirconia at $30.2^{\circ}=2 \theta$ is dominating. Broad peaks in the XRD patterns are a result of small crystal sizes. The powder is very moisture sensitive and the diffusion of water to the crystallite surface induces the martensitic tetragonal to monoclinic $(\mathrm{t} \rightarrow \mathrm{m})$ phase transformation [9]. During water storage the two monoclinic reflections (-111 and 111) grows in intensity and the (101) reflection decreases, indicating a $t \rightarrow m$ transformation.

\section{IR studies}

The results from the analysis of unmodified and methanol treated zirconia samples are plotted in Fig. 2 The observed carbonate species on the synthesized zirconia are: ionic carbonate $\mathrm{CO}_{3}{ }^{2-}: 1444 \mathrm{~cm}^{-1}$, bidentate bicarbonate $\mathrm{HCO}_{3}{ }^{-}: 1598$ $\mathrm{cm}^{-1}$, bidentate covalent surface carbonate " $\mathrm{CO}_{3}{ }^{\prime}: 1558$ and $1325 \mathrm{~cm}^{-1}$ and finally ionic carboxylate $\mathrm{CO}_{2}^{-}: 1423 \mathrm{~cm}^{-1}$. The intensities of the ionic carbonate and carboxylate are the same, creating a double peak in the IR spectrum. The bidentate covalent surface carbonate is just shoulders to the double peak and the bicarbonate is a small peak and only a shoulder to the bidentate covalent surface carbonate peak. After exposure to methanol three peaks at 1614,1471 and $1359 \mathrm{~cm}^{-1}$ respectively appears.

\section{Autosorbtion}

In the autosorbtion study different zirconia samples were analyzed. In Fig. 3 the result from the analysis of the untreated zirconia and the methanol treated zirconia are plotted. In both samples a discontinuity is observed at relative pressure of $\sim 0.1$ and for the unmodified zirconia this increase is 6 times larger than for the methanol treated zirconia sample. 
From Tab. 1 it is observed that ethylene glycol does not work as an activator, for this reason ethylene glycol modified zirconia were subjected to an autosorbtion analysis and the results are also plotted in Fig. 3. In this sample the slope steepens at a relative pressure of $\sim 0.16$. Comparing with the methanol treated sample, 7 times as much water can be added without any significant increase of the relative pressure.

The methanol treated zirconia was analyzed further and the analyses were stopped at different relative pressures. The zirconia samples were handled to prevent further phase transition. The XRD patterns obtained from these samples are illustrated in Fig. 4. It is observed that some of the zirconia is phase transformed at a relative pressure of 0.05 and the level of phase transformation increases with increasing relative pressure. Again the reference sample only contains traces of the monoclinic phase prior to water storage and the tetragonal 101 reflection of zirconia at $30.2^{\circ}=2 \theta$ is dominating. The growth in intensity of the two monoclinic reflections (-111 and 111) indicates a $t \rightarrow m$ transformation.

\section{Discussion}

\section{Evaluation of phase transformation activators}

In an effort to inactivate the carbonates towards reaction initiator molecules, various molecules were used to modify the zirconia surface. Very little phase transformation was detected in the reference sample without any activator added. Apparently, the initiator species derived from the triazine was almost completely 'consumed' by the carbonates present at the surface of the zirconia particles.

When the zirconia surface is covered with carbonates higher amounts of initiator molecules are needed to initiate the phase transformation - as carbonates are reactive towards water and that reaction will lower the number of water molecules reacting with the surface. This is crucial for the phase transformation rate in resin, as the activity of water is low. This is observed from the water storage experiments, where the matrix dispersed methanol treated zirconia phase transforms much faster than the unmodified matrix dispersed samples. Already after $8 \mathrm{~h}$ the methanol treated samples have a higher monoclinic volume fraction than the untreated samples have after 21 days.

From the results of the test of potential activators it is concluded that alcohols, thiols and primary amides are able to activate the zirconia surface. An exception from alcohols is short chained di- and tri-alcohols with less than five carbon molecules separating the $\mathrm{OH}$-groups e.g. ethylene glycol, glycol and 1,4 butanediol. These molecules inhibit the phase transformation. It has been experimentally shown that molecules able to make a bidentate bond to the zirconia surface have a stabilizing effect, e.g., the ethylene glycol treated sample did not phase transform at all as a result of exposure to ambient atmosphere (not shown). The untreated zirconia is previously proven to have a monoclinic volume fraction of 0.68 after exposure to ambient atmosphere [12]. Ethylene glycol is a bidentate molecule, which can potentially stabilize the tetragonal zirconia in the same manner as trimethoxy silanes and phosphates by binding two $\mathrm{OH}$-groups across a $\mathrm{Zr}-\mathrm{O}-\mathrm{Zr}$ bridge because of a chelate effect. Probably an increased strain in the crystal lattice results [13]. 
In order to avoid bridge bonding the activator should be monodentate (only able to bind with one group) or the functional groups should be far away from each other. The distance between the functional groups can be determined by intervals of C-bonds in the dialcohol. Ethylene glycol, 1,3 propanediol and 1,4 butanediol block the phase transformation, whereas 1,5 butanediol does not. The distance between the bonding groups should be more than 4 carbon bonds in order to avoid stabilizing the tetragonal phase. Actually 1,5 butanediol results in a higher $v_{m}$ than methanol. Possibly $1 \mathrm{mmol}$ activator not is enough to inactivate all the carbonates on the surface and since 1,5 butanediol can react with two carbonates it can potentially deactivate a larger fraction of the carbonates. Methanol is smaller than 1,5 butanediol and is for this reason chosen. Addition of the smallest possible amount of solvent is preferable for the mechanical properties of the dental composites.

\section{IR spectroscopy}

During the calcination of the zirconia powder, remaining solvent from the drying process will burn and result in formation of $\mathrm{CO}_{2}$. This is known to react with zirconia surfaces under formation of carbonates. The adsorption of $\mathrm{CO}_{2}$ on zirconia has been widely studied [14]. The kind of species formed on the surface of zirconia is very dependent on the process condition such as temperature, amount of $\mathrm{CO}_{2}$ and the surface of the zirconia. All the observed carbonates can react with methanol and form methyl carbonates. Methyl carbonates give rise to IR spectra with three significant peaks at: 1600, 1474 and $1370 \mathrm{~cm}^{-1}$ [15]. Methanol treatment of the zirconia particles give rise to peaks at 1614, 1471 and $1359 \mathrm{~cm}^{-1}$. The formation of a substituted carbonate can therefore be observed in IR as a change of the carbonate peaks into the substituted species peaks. The above mentioned peaks are all assigned to the $\mathrm{C}-\mathrm{O}($ or $\mathrm{C}=\mathrm{O})$ vibrations as these are the modes with the highest extinction and are by far the easiest way to recognizing a change in carbonates on the surface of zirconia.

\section{Autosorbtion}

Looking at the autosorbtion curves of water on different zirconia surfaces several observations can be made. It is observed that the unmodified zirconia has a very steep adsorption curve at a partial pressure of $\sim 0.1$. This sharp adsorption increase can also be found in other autosorbtion studies of zirconia with surface modification. The increase varies in size and a little in position (in relative pressure). The unmodified and methanol modified zirconia differ significantly in the amount of water adsorbed on zirconia. The origin of the increase cannot be associated with phase transformation of zirconia since some phase transformation is observed already at $\mathrm{p} / \mathrm{p} 0=0.05$ (Fig. 4). The increase is more likely to be associated with adsorption/absorption of water on the surface of zirconia.

The results show that with a more hydrophobic surface the discontinuous part of the curve appears at a higher relative pressure. We cannot explain the reason for the differences in the magnitude of this increase. It could, however, be a result of the reaction between water and the surface carbonates. The discontinuity has the same magnitude for the untreated and the ethylene glycol treated sample. We speculate that the ethylene glycol prefers to bind the zirconia surface due to the possibility of bidentate binding, rather than reacting with the surface carbonates, 
this can explain the differences. In the methanol treated samples the methoxylated carbonates are unable to react with water and can for this reason not absorb as much water as the unmodified and ethylene glycol treated samples. This leads to an increase in the relative pressure comparing with the two other samples.

\section{Conclusion}

Carbonates on the zirconia surface reduce the transformation rate in the composite due to competing reactions with the initiator molecule water. The competing reaction can be inhibited by modification with alcohols, thiols and molecules with other functional groups, which react with the carbonates. The carbonates are prevented from reacting with water - and thus the molecules works as activators making the phase transformation faster. Through methanol treatment of the zirconia prior to dispersion in a polymer matrix, the monoclinic volume fraction can be increased from 0.47 within 21 days of water storage to 0.67 after $48 \mathrm{~h}$ water storage, with most of the phase transition occurring within the first $8 \mathrm{~h}$. Dialcohols and polyalcohols, however, such as ethylene glycol, which have the possibility for bidentate coordination, hinder phase transformation.

Acknowledgments: Financially support from DentoFit A/S is gratefully acknowledged. We thank Dr. Keld West for assistance with the autosorbtion studies.

\section{References}

[1] Powers JM, Sakaguchi RL (2006) In: Craig's Restorative Dental Materials, 12th ed. Mosby Elsevier, United States of America

[2] Kelly PM, Rose LRF (2002) Progress in Materials Science 47:463

[3] Skovgaard M, Almdal K, van Lelieveld A Submitted for publication

[4] Skovgaard M, Almdal K, van Lelieveld A Submitted for publication

[5] Sato T, Shimada M (1985) J Am Ceram Soc 68:356

[6] Bianchi D, Chafik T, Khalfallah M et al (1993) Applied Catalysis A-General 105:223

[7] Van Lelieveld, A, Almdal, K, Linderoth, S and Sorensen, BF (2005) WO2005099652-A1; NO200604920-A; EP1737415-A1; AU2005232365-A1; CN1950053-A; BR200509889-A; MX2006011038-A1; JP2007532589-W; KR2007015946-A; EP1737415-B1; US2008119585-A1; DE602005006549-E; EP1952793-A2; ZA200608230-A; KR858373-B1; ES2307170-T3;

[8] Skovgaard M, Ahniyaz A, Sorensen BF et al (2010) Journal of the European Ceramic Society 30:2749

[9] Van Lelieveld, A, Nielsen, MS, Almdal, K and Linderoth, S. (2007) WO2007104312-A2; WO2007104312-A3; EP1996144-A2; US2010016465-A1

[10] Skovgaard M, Almdal K, van Lelieveld A (2010) J Mater Sci 45:6271

[11] Toraya H, Yoshimura M, Somiya S (1984) J Am Ceram Soc 67:C119

[12] Skovgaard M, Almdal K, van Lelieveld A Accepted by J Mater Sci

[13] Jiao XL, Chen DR, Xiao LH (2003) J Cryst Growth 258:158

[14] Bianchi D, Chafik T, Khalfallah M et al (1994) Applied Catalysis A-General 112:219

[15] Jung KT, Bell AT (2001) Journal of Catalysis 204:339 


\section{Captions}

Tab. 1 effect of addition of $1 \mathrm{mmol}$ of potential activators to the resin on the monoclinic volume fraction of zirconia caused by initiation of phase transformation by 2-(4-methoxystyryl)-4,6bis(trichloromethyl)-1,3,5-triazine exposed to blue light

Fig. 1 XRD patterns of matrix dispersed unmodified zirconia after (a) 0 hour, (b) 3 days and (c) 21 days water storage at $40^{\circ} \mathrm{C}$ and of a methanol modified matrix dispersed zirconia after water storage at $40^{\circ} \mathrm{C}$ in (d) 8 hours and (e) 3 days.

Fig. 2 IR Spectra of a) zirconia and b) methanol treated zirconia

Fig. 3 Autosorbtion curves of $\boldsymbol{\square}$ ) methanol treated zirconia, $\mathbf{\Delta}$ ) untreated zirconia and $\bullet$ ) ethylene glycol treated zirconia.

Fig. 4 XRD patterns of methanol treated zirconia (a) before and (b) after autosorbtion stopped at $\mathrm{p} / \mathrm{p} 0=0.05,(\mathrm{c}) \mathrm{p} / \mathrm{p} 0=0.1,(\mathrm{~d}) \mathrm{p} / \mathrm{p} 0=0.9$

\section{Tables}

Tab. 1 effect of addition of $1 \mathrm{mmol}$ of potential activators to the resin on the monoclinic volume fraction $\left(v_{m}\right)$ [11] of zirconia caused by initiation of phase transformation by 2-(4-methoxystyryl)4,6-bis(trichloromethyl)-1,3,5-triazine exposed to blue light

\begin{tabular}{lc}
\hline Tested activators & $\boldsymbol{v}_{\boldsymbol{m}}$ \\
\hline Tert-Butylamine & 0 \\
Diethylamine & 0 \\
Triethylamine & 0 \\
Ethylenediamine & 0 \\
& \\
Methanol & 0.53 \\
Iso-propanol & 0.55 \\
Iso-octanol & 0.46 \\
Ethylene glycol & 0 \\
1,3-propanediol & 0 \\
1,4-butanediol & 0 \\
1,5-pentanediol & 0.63 \\
Glycerol & 0 \\
Octane thiol & 0.50 \\
& \\
$N, N$-Dimethylformamide & 0 \\
Chloroform & 0 \\
Acetamide & 0.24 \\
Cyanamide & 0 \\
Unmodified zirconia & 0 \\
\hline
\end{tabular}




\section{Figures}

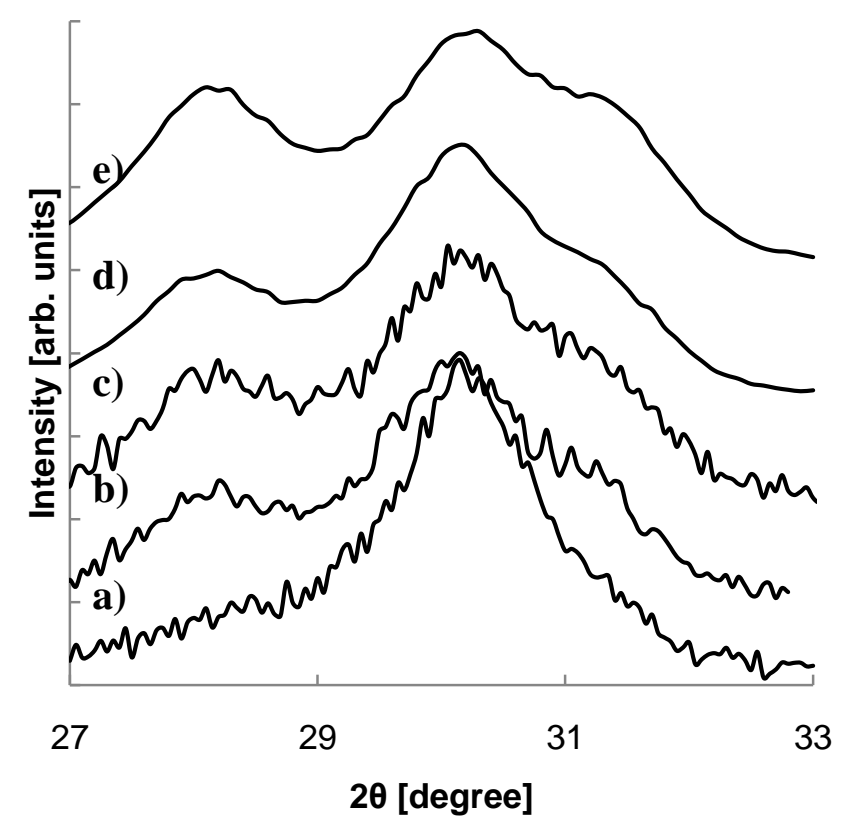

Fig. 1 XRD patterns of matrix dispersed unmodified zirconia after (a) 0 hour, (b) 3 days and (c) 21 days water storage at $40^{\circ} \mathrm{C}$ and of a methanol modified matrix dispersed zirconia after water storage at $40^{\circ} \mathrm{C}$ in (d) 8 hours and (e) 3 days.

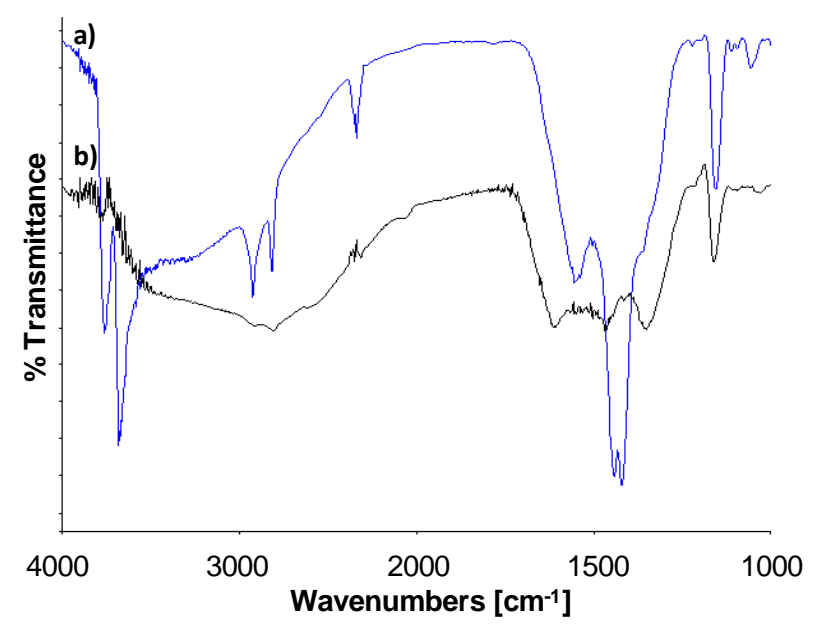

Fig. 2 IR Spectra of a) zirconia and b) methanol treated zirconia 


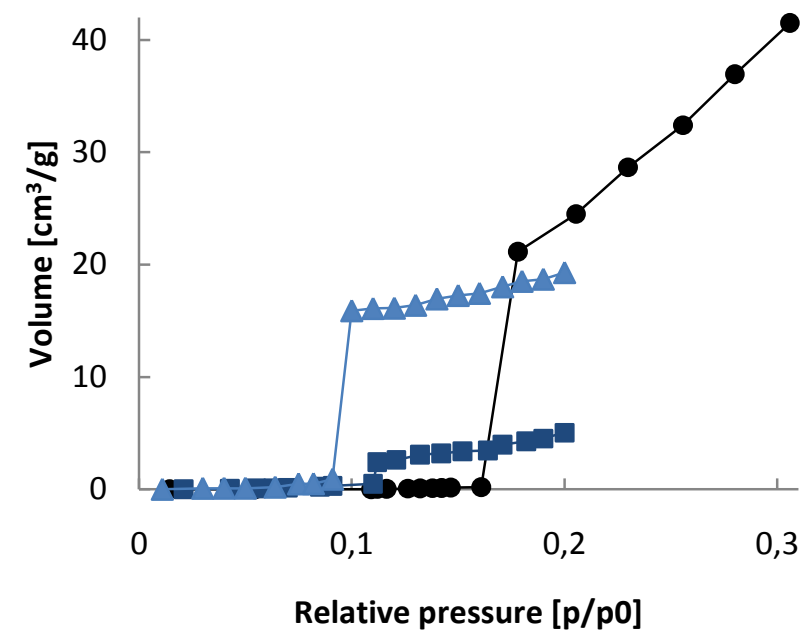

Fig. 3 Autosorbtion curves of $\boldsymbol{\square}$ ) methanol treated zirconia, $\Delta$ ) untreated zirconia and $\bullet$ ) ethylene glycol treated zirconia.

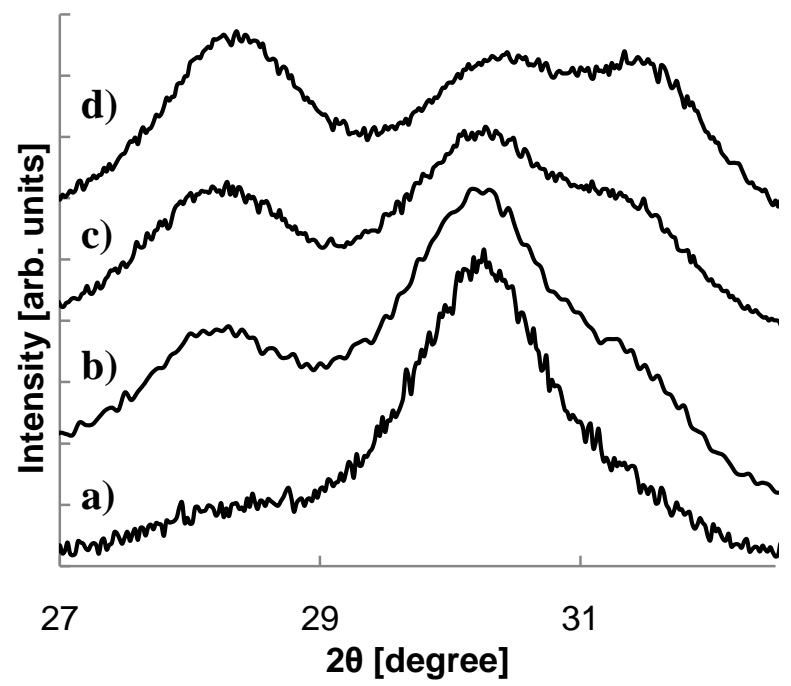

Fig. 4 XRD patterns of methanol treated zirconia (a) before and (b) after autosorbtion stopped at $\mathrm{p} / \mathrm{p} 0=0.05$, (c) $\mathrm{p} / \mathrm{p} 0=0.1$, (d) $\mathrm{p} / \mathrm{p} 0=0.9$ 